\title{
Contexto
}

\section{Una posibilidad de pensar sobre el devenir de nuestras prácticas escriturales a partir de la crisis}

Editorial

\author{
Yuliana Gómez Zapata* \\ Directora Editorial
}

Desde hace algunos años he venido insistiendo en espacios de editores, con amigos, de dirección universitaria y en lo íntimo de mi hogar, sobre la necesidad de reflexionar respecto de los procesos de medición, no solo desde Minciencias en Colombia sino en general, asunto que me ha costado el desdén de algunos cercanos y el aprecio de otros-otras que para mí han sido muy importantes.

Estas preguntas que me he hecho alrededor del padecimiento que ha sido el tenernos que medir como revistas en condiciones desiguales, van encaminadas hacia el cómo y el para qué de esas mediciones, pues

(...) esas reflexiones estaban marcadas por la sensibilidad que me genera participar de escenarios académicos y escuchar a algunos colegas cuestionar públicamente la forma de medición de las revistas científicas en Colombia, pero también aquellos que la avalan; y digo que me genera sensibilidad porque es el martirio con el que los y las editores de revistas nos enfrentamos en el día a día (Arias, et al, p.147).

Y, sigo insistiendo con este asunto porque nuestra conducta pareciera ser casi patológica al privilegiar la lógica bibliométrica por encima de la utilidad pública del conocimiento (Gómez-Zapata, 2019, p.35). Sigo insistiendo en que estamos confundiendo el sentido de nuestras prácticas escriturales y, por tanto, el de nuestras publicaciones. También insiste Gómez-Morales (2018) cuando plantea que el estado “(...) formula políticas de ciencia cuyas consecuencias sociales y culturales se pasan por alto al confundir el indicador con las metas de política” (p.273).

\footnotetext{
* Directora Editorial de la Revista En-Contexto. Contadora Pública y MSc. en Ciencias Contables. Miembro de la Red Colombiana de Editores y Revistas Contables REDITORES. Directora del Grupo de Investigación Observatorio Público y profesora investigadora del Tecnológico de Antioquia, Medellín - Colombia. ygomezza@tdea.edu.co

ORCID: http://orcid.org/0000-0003-4134-4056
} 


\section{Contexto Gimerzanaut.}

Este contexto trágico ${ }^{1}$ de las revistas y de los editores que hemos venido recalcando en diferentes espacios, me genera, de nuevo, preocupación en la medida en que nuestras prácticas siguen atendiendo a las mismas lógicas de individualidad, reticencia, insolidaridad y poca empatía con el sentido de nuestra presencia en las universidades; tampoco la pandemia que vivimos hoy y que desde hace un poco más de 100 años no se presentaba en el mundo, nos va dejando enseñanzas importantes para cambiar nuestro lugar y la utilidad de lo que agenciamos, de lo que se escribe en las revistas que dirigimos como plataformas académico-políticas que pueden cambiar el mundo en el que vivimos.

Debo confesar que tenía la esperanza de escribir sobre el cambio que nos ha producido la COVID-19, ${ }^{2}$ a lo cual yo comencé a llamar "la crisis", pero también debo confesar que soy escéptica sobre esa posibilidad de cambio, pues veo en la cotidianidad las mismas prácticas de poca empatía e insolidaridad de quienes nos cohabitan. Pensaría que nuestro rol como editores de revista y articulistas no se escapa a tales. Sigo pensando en el sinsentido que nos atrapa como académicos, pero apelo a movilizar nuestra consciencia, porque "(...) si no somos conscientes, no podemos descolonizar nuestras formas de pensar, de ver el mundo, de vivir. Y es esta emergencia la que pone en tensión el sentido de nuestro quehacer académico y escritural" (Gómez-Zapata, 2020, p.38).

Ahora bien, ya después de haberme quejado lo suficiente y reiterar mi preocupación y descontento con lo que en algún momento planteara el colega Fredy León Paime $^{3}$ en su "Carta al editor contable" (2016), creo que es oportuno avanzar hacia posibilidades de concientización, como ya lo plantee, pero también hacia prácticas de conversación y discusión constante con nuestros equipos de trabajo, con los amigos y con los contrarios; apelo a la conversación (Quijano, 2016) como posibilidad inconmensurable de reflexión, pues este trabajo dispendioso y valiente que hacemos los editores y las editoras en el cotidiano, requiere contextos de reflexividad constante que a veces solo lo permite el "tinto" conversado.

Tenemos la posibilidad inmensa de re-pensar nuestras prácticas académicas, escriturales y de publicación a partir de lo que hemos vivido este 2020, tenemos también el compromiso de ser capaces de reconocer nuestros desaciertos y nuestros aporte en la co-construcción de conocimiento experto mediante el texto escrito, pero también de reconocer en nosotros esa capacidad de generar acciones pedagógicas para aportar a la comprensión y transformación de realidades concretas en comunidades donde prima la experiencia y la doxa, siempre con solidaridad académica y epistémica.

\footnotetext{
${ }^{1}$ Lo planteo de forma alegórica.

2 Pandemia desatada en 2019 en la ciudad de Wuhan (China) y conocida como la enfermedad del Coronavirus (COVID 19), altamente infecciosa y que ha cobrado la vida de casi 2 millones de personas en el mundo.

${ }^{3}$ Contador Público de la Universidad Nacional de Colombia y gran amigo, quien anda siempre ocupado y atinado con estos temas.

${ }^{4}$ Así se le llama a la taza de café en Colombia.
} 
Esta invitación pedagogizante, siempre académico-política, es con la firme intención de que nos pensemos desde nuestras propias posibilidades para creer en los y las otras, para aportar a mejorar nuestra vida y la de aquellos que nos acompañan, para que nuestra escritura sea una ventana siempre abierta a la humildad, la humanidad, la empatía, pero, sobre todo, a la solidaridad. Esta es mi apuesta como editora de En-Contexto y mi invitación, desde el afecto, para quienes quieran sumarse.

\section{Referencias}

Arias, J., et al. (2020). Aproximaciones contextuales sobre el devenir de las revistas contables colombianas. Perspectivas plurales de los editores. Contaduría Universidad de Antioquia, 77, 131-165. Doi: https://doi.org/10.17533/udea. rc.n77a05

Gómez-Morales, Y. (2018). Abuso de las medidas y medidas abusivas. Crítica al pensamiento bibliométrico hegemónico. Anuario Colombiano de Historia Social y de la Cultura, 45(1), 269-290.

Gómez-Zapata, Y. (2020). Redes Colaborativas. Una posibilidad de movilizar el conocimiento desde la solidaridad. En-Contexto, 8(12), 37-39.

Gómez-Zapata, Y. (2019). ¿Cómo y para qué nos miden? Crítica reflexiva sobre el proceso de medición Publindex-Colciencias para revistas científicas en Colombia. En-Contexto, 7(11), 35-37.

León-Paime, E. (2016). Carta al editor contable. Contaduría Universidad De Antioquia, 67, 17-20. https://revistas.udea.edu.co/index.php/cont/article/view/325304

Quijano, O. (2016). La conversación o el 'interaccionismo conversacional'. Pistas para comprender el lado oprimido del(os) mundo(s). file://C:/ Users/ygomezza/Downloads/Conversaci\%C 3\%B 3 n \% 20 o\% 20 interaccionismo $\% 20$ conversacional $\% 20$ Calle $\% 2014 \% 202017 . p d f$

\section{Para citar este artículo:}

Gómez-Zapata, Y. (2020). Una posibilidad de pensar sobre el devenir de nuestras prácticas escriturales a partir de la crisis. En-Contexto, 8(12), 37-39. 